\title{
Variability of the Critical Frequency foF2 for Equatorial Regions during Solar Cycle's Minima and Maxima at Ouagadougou and Manila Stations
}

\author{
Kaboré M'Bi1,2, Zerbo Jean Louis ${ }^{2 *}$, Zoundi Christian1, Ouattara Frédéric ${ }^{1}$ \\ ${ }^{1}$ Laboratoire de Recherche en Energétique et Météorologie de l’Espace (LAREME), Université Norbert Zongo, Koudougou, \\ Burkina Faso \\ ${ }^{2}$ Laboratoire de Matériaux, d’Héliophysique et Environnement (LAMHE), Université Nazi Boni, Bobo Dioulasso, \\ Burkina Faso \\ Email: *jeanlouis.zerbo@gmail.com
}

How to cite this paper: M'Bi, K., Louis, Z.J., Christian, Z. and Frédéric, O. (2019) Variability of the Critical Frequency foF2 for Equatorial Regions during Solar Cycle's Minima and Maxima at Ouagadougou and Manila Stations. International Journal of Geosciences, 10, 833-844.

https://doi.org/10.4236/ijg.2019.1010047

Received: August 13, 2019

Accepted: October 5, 2019

Published: October 8, 2019

Copyright $\odot 2019$ by author(s) and Scientific Research Publishing Inc. This work is licensed under the Creative Commons Attribution International License (CC BY 4.0).

http://creativecommons.org/licenses/by/4.0/

\begin{abstract}
In this paper we report on the foF2 variabilities for two equatorial regions (Ouagadougou: Lat. $12.4^{\circ} \mathrm{N}$; Long. $358.5^{\circ} \mathrm{E}$, Dip. $1.43^{\circ} \mathrm{S}$; and Manila: Lat. $14^{\circ} 36^{\prime} 15.12^{\prime N} \mathrm{~N}$; Long. $120^{\circ} 58^{\prime} 55.92^{\prime \prime E}$; Dip. $0.6^{\circ} \mathrm{S}$ ) during solar cycles 20 and 21 minima and maxima phases. Many previous works have argued on the diurnal and seasonal variation of foF2 for different solar events conditions for latitudinal position. But there are few investigations for Africa equatorial region longitudinal variation. The present paper's goal is to outline possible similarity in foF 2 behavior between variations for better understanding of physical process lead to some observed phenomenon in Asia-Africa equatorial sector. The F-layer critical frequency (foF2) data observed from the two equatorial ionosonde stations have been used for the present comparative study. The results show significant similarity between the critical frequency (foF2) seasonal variations over the time intervals 1976-1996. During day-time measured data from Manila station are higher than those from Ouagadougou station. That may lie in that Manila is closer to equatorial ionization crest region. During solar minimum phase, the longitudinal variation of foF2 shows two crossing points (11:00 UT and 22:00 UT) between the foF2 profiles form the two stations for all seasons regardless of the solar cycle. However during intense solar activity condition, the number of crossing-point between measured data from Manila and Ouagadougou stations varies by seasons and solar cycle. This phenomenon may be due to the compilations of severe activities (storms, coronal mass ejection, heliosheet fluctuations) during the solar maximum phases.
\end{abstract}




\section{Keywords}

Critical Frequency (foF2), Longitudinal Variation, Seasonal, Solar Cycle

\section{Introduction}

The ionosphere is one of the most important layers of the Earth atmosphere. This layer ionized by solar and cosmic radiation is very important for waves and their propagations. Understand the behavior of this region's parameters during solar activity and solar cycle phases may be useful for investigations on solar variability and its terrestrial impacts. To better seize the behavior of the ionosphere many reports have highlighted the variability of its critical frequency foF 2 profiles during various seasons, day, time, solar events, and latitude [1]-[11]. [12] had reported on the variation of this ionospheric parameter through its in situ measurements in Africa equatorial region and classified foF2 diurnal profiles as follow: 1) morning peak profile characterized by a predominance morning peak; 2) plateau profile; 3 ) dome profile; 4) reverse profile characterized by predominant afternoon peak; and 5) noon bite out profile due to the presence of double peaks (morning and afternoon peaks) with trough around midday. All these previous studies had provided suggestions and help on the improvement of the prediction of the equatorial ionosphere behavior for human well-being. Few investigations have reported on a comparison between in situ measurements from Africa regions and Asia or America one in order to address the lack of data in most Africa regions. Comparative investigations can help to predict solar events when similarities in ionospheric parameters behavior are stronger.

Our present investigation fits into this overall objective and constitutes a contribution to better understand the dynamic of ionosphere in two equatorial regions (Ouagadougou: Lat. $12.4^{\circ} \mathrm{N}$; Long. $358.5^{\circ} \mathrm{E}$, Dip. $1.43^{\circ}$ in Africa and Manila: Lat. $14^{\circ} 36^{\prime} 15.12^{\prime \prime N}$; Long. $120^{\circ} 58^{\prime} 55.92 " E$; Dip. $0.6^{\circ} \mathrm{S}$ in Asia).

In the current study, foF 2 data from Ouagadougou and Manila ionosonde stations are used to illustrate the various characteristics of F-Layer of the ionosphere through is critical frequency foF2. Seasonal and solar activity effects on ionosphere are performed during solar cycles 21 and 21 minima and maxima for Ouagadougou and Manila. In Section 2, data and investigation methodology are outlined. Results and physical phenomena are discussed in Section 3. The Final Section presents our findings and summarizes the paper.

\section{Data and Methodology}

\subsection{Data}

1) The ionospheric parameter studied is the critical frequency of the F2 layer (foF2) obtained from the SPIDR database (URL: http://spidr.ionosonde.net/spidr/;

2) The values of sunspots Rz taken from http://sidc.oma.be/sunspot-data/; 3) The geomagnetic index aa used to selected quiet days conditions are from 
http://isgi.unistra.fr/data_download.php. Figure 1 is an example of pixel diagram displaying aa index as a table and showing quiet activity [13] [14].

\subsection{Methodology}

The Solar cycle phases are determined using sunspot number Rz [15] and criteria fully described in many works [16] [17]: 1) the minimum phase: $\mathrm{Rz}<20$; 2) the ascending phase: $20 \leq \mathrm{Rz} \leq 100$ and $\mathrm{Rz}$ greater than the previous year's value; 3) the maximum phase: $\mathrm{Rz}>100$; 4) the decreasing phase: $100 \geq \mathrm{Rz} \geq 20$ and $\mathrm{Rz}$ less than the previous year values.

Local (north hemispheric) seasons are classified as followed: winter (December, January, and February); spring (March, April, May); summer (June, July, August) and autumn (September, October and November).

To perform our study, we proceed as follow:

1) At solar maximum and solar minimum: select days with highest $\mathrm{Rz}$ and the lowest $\mathrm{Rz}$ respectively;

2) Choose five days the most disturbed (highest aa index) and five quietest (aa lowest index);

3) Monthly and seasonal average (hourly) of foF2 per cycle and solar activity.

\section{Results and Discussion}

This section presents and analyzes the results of our investigations in other to allow comparison between measurements from the Africa and Asia equatorial regions.

\subsection{The foF2 Diurnal Profiles}

Figures 2-5 present the diurnal variation of foF2 during geomagnetic quiet activity for solar minima and disturbed geomagnetic activity for solar maxima at Ouagadougou and Manila stations over the solar cycle 21 (1976-1986) and the solar cycle 22 (1986-1996). Each figure show the seasonal ((a) winter; (b) spring; (c) summer; (d) autumn) behavior of foF2.

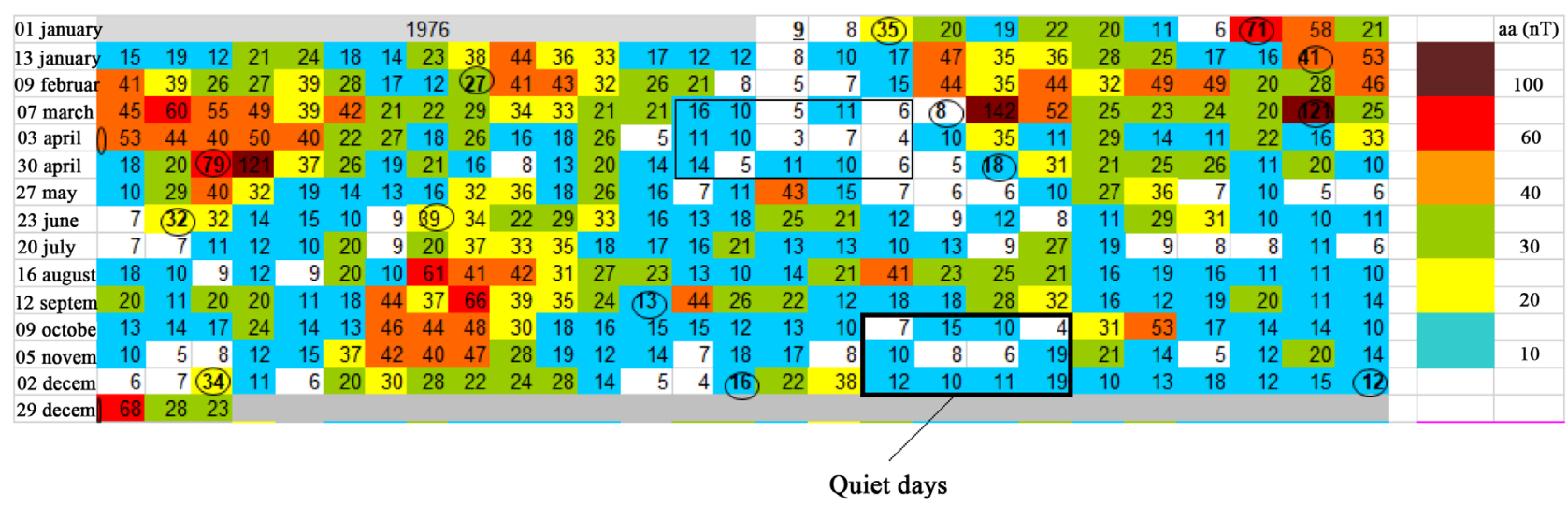

Figure 1. Pixel diagram of year 1976 illustrating geomagnetic activity classes. Each line shows solar rotation, successive lines solar rotations, and each number the daily average of solar wind speed. Circle indicates the date of storm/coronal mass ejection (CME). 


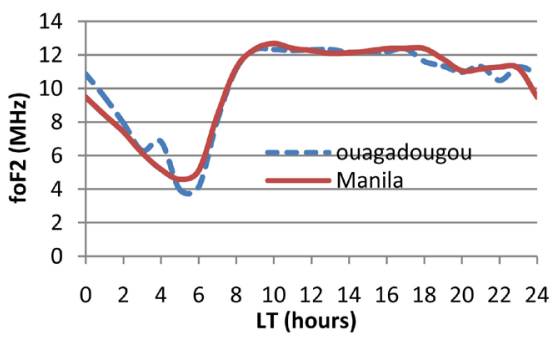

(a)

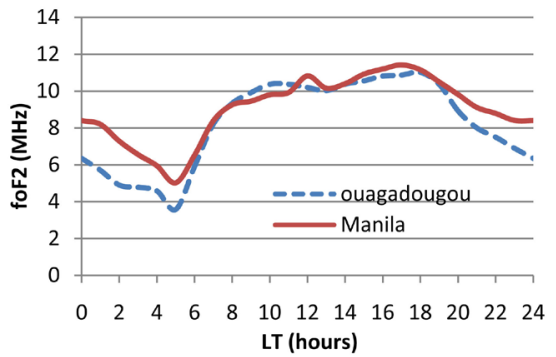

(c)

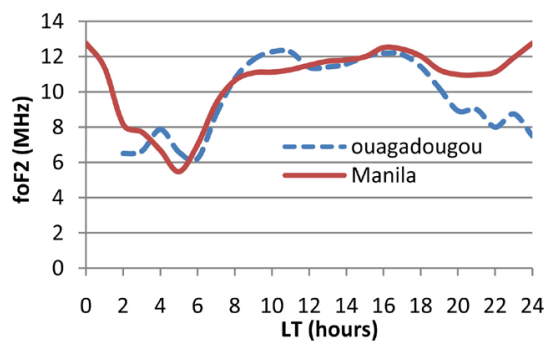

(b)

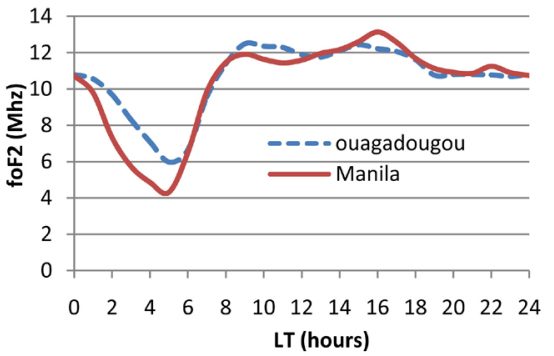

(d)

Figure 2. Diurnal variations of foF2 during cycle 20 maximum phase: (a) winter; (b) spring; (c) summer; (d) autumn.

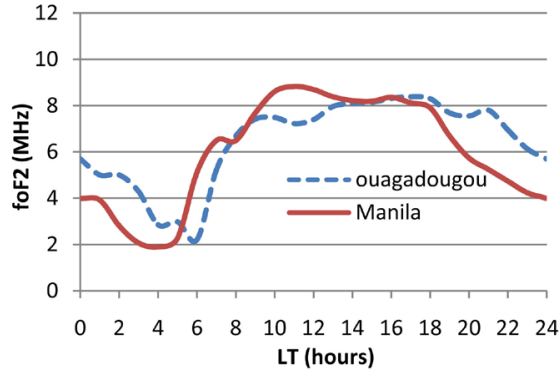

(a)

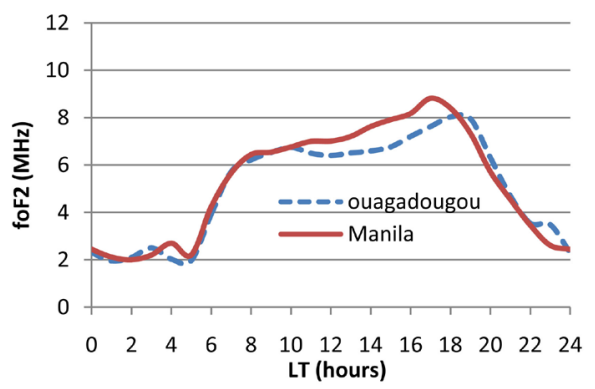

(c)

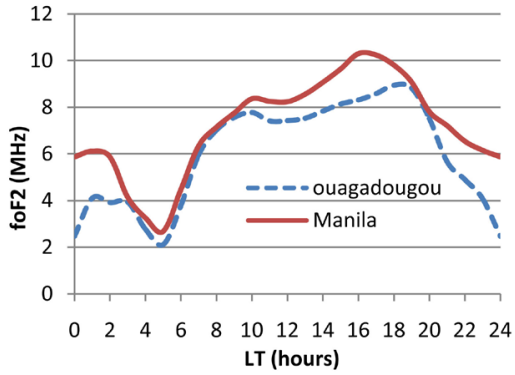

(b)

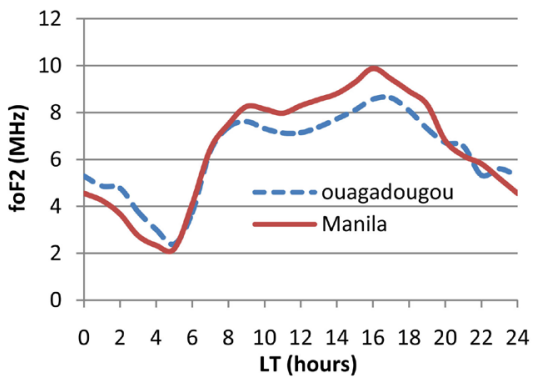

(d)

Figure 3. Diurnal variations of foF2 during cycle 20 minimum phase: (a) winter; (b) spring; (c) summer; (d) autumn.

All the profiles show that the highest values of foF2 are recorded during sunspot cycle maximum phase for all the seasons testifying to the linear dependence between sunspot number and the critical frequency foF 2 as reviewed in many previous works [18]-[23].

From these figures it also appears that the gap $(\Delta$ foF 2$)$ between profiles from 


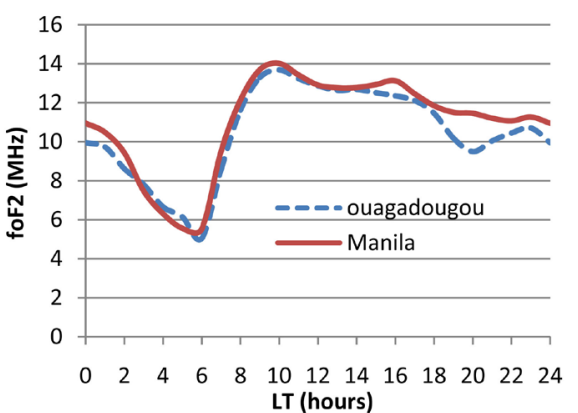

(a)

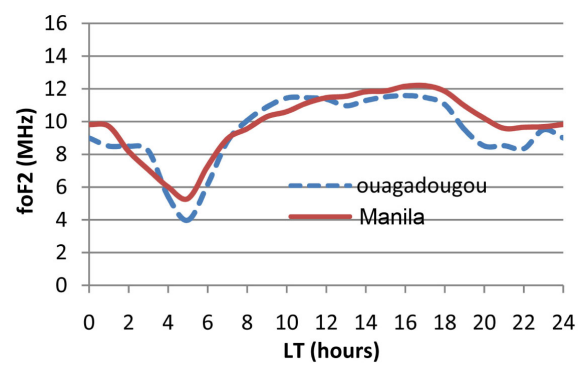

(c)

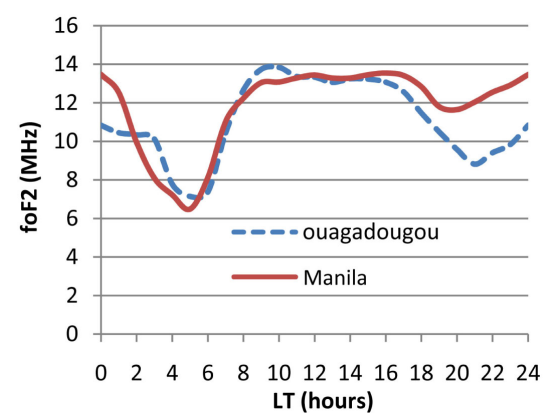

(b)

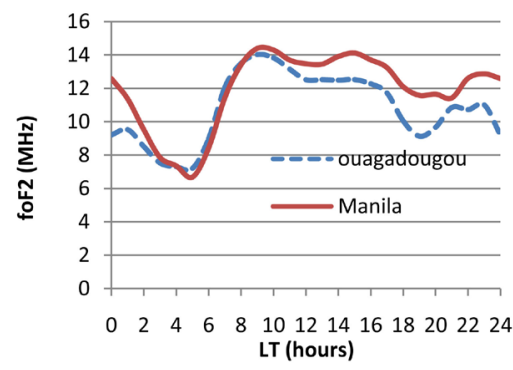

(d)

Figure 4. Diurnal variations of foF2 during cycle 21 maximum phase: (a) winter; (b) spring; (c) summer; (d) autumn.

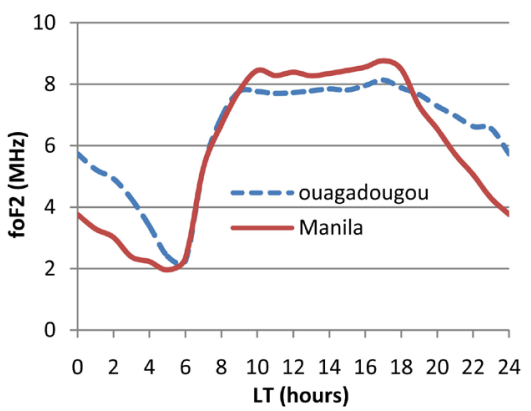

(a)

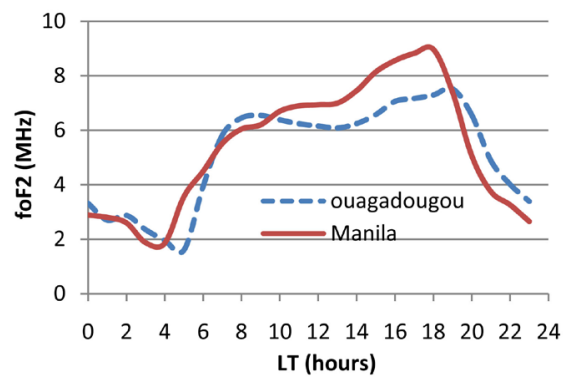

(c)

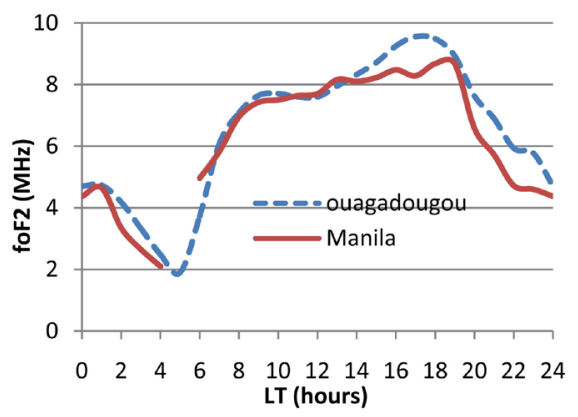

(b)

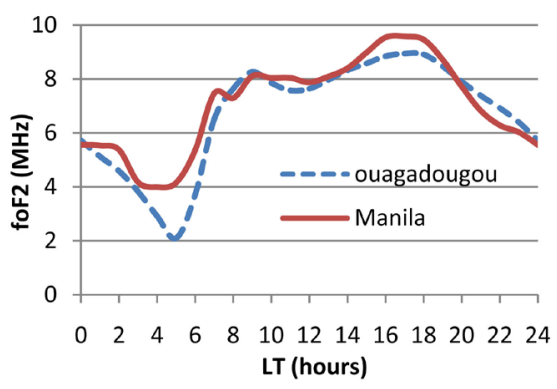

(d)

Figure 5. Diurnal variations of foF2 during cycle 21 minimum phase: (a) winter; (b) spring; (c) summer; (d) autumn.

Manila and Ouagadougou stations measurements are not significant for all seasons except on Figure 2(b) at 00:00 LT where $\Delta$ foF2 $=5.26 \mathrm{Mhz}(12.76 \mathrm{MHz}$ for Manila and 7.50 MHz for Ouagadougou). This gap may be a manifestation of 
local disturbance. The profiles of foF2 at the two stations are similar most of the time and present peaks or troughs very or fairly pronounced. During daytime, the two profiles are superimposable with perturbations on the evolutions of some profiles due to longitudinal irregularities of the F-layer parameters has reviewed in [24] [25]. The most important differences between the foF 2 values at the two stations occur tonight. During this period, the electric dynamo process is predominant, and foF2 profiles differ greatly at Ouagadougou and Manila stations because of ionospheric plasma irregularities and instability [26]. The local effects on equatorial electrojet process [27] may induce differences between the two stations' measurements. The dynamics of the migratory tides, the diurnal propagation of the tides and the meridional winds lead to longitudinal variations of the electrojet [28] [29] [30]. A qualitative analysis of foF2 profiles for the two stations shows the diurnal profiles reported by [12]: "Noon bite out" or "B" profile characterized morning; "Reversed" or " $\mathrm{R}$ " profile characterized by a single peak at evening; "Dome" or " $D$ " profile characterized by a double peak (morning and evening); "Morning Peak" or " $M$ " profile defined by a single peak at by a single maximum around noon; "plateau" or "P" profile characterized by an ionization plateau during daytime.

In general, the recorded values of foF 2 at Manila station are higher than those from Ouagadougou station. The Table summarizes the most important seasonal values of foF 2 during solar cycle and solar activity. The gap between the data from these two equatorial regions may be due to the fact that Manila is closer to the crest of ionization during daytime. Tonight, ionization is largely due to cosmic radiation and that could explain the variation in the relative position of the two profiles during that time since the two stations are not at a same geographic position. Except that, equinoctial asymmetry is observed during all the sunspot cycle phases over the two solar cycles (Figure 2(b) and Figure 2(d); Figure 3(b) and Figure 3(d); Figure 4(b) and Figure 4(d); Figure 5(b) and Figure 5(d)). Solstice' anomalies [31] are observed in the profiles during the maximum and the minimum phases for solar cycle 21 (Figure 4(a) and Figure 4(c), Figure 5(a) and Figure 5(c)) and only during the maximum phase of cycle 20.

\section{2. foF2 Seasonal Variations Comparison}

Figures 6-9 give an overview of a comparative between the two stations measurements during the period 1976-1996 for different seasons ((a) winter; (b) spring; (c) summer; (d) autumn).

During solar minimum phases the foF 2 profiles show two crossing points for all the seasons. These crosses occur around 11:00 UT and 22:00 UT (Figure 7 and Figure 9). During these times intervals we can assume that there is no longitudinal effect on the critical frequency evolution. In addition the two points do not change from one cycle to another. Unlike minimum phase, there are several intersection points during maximum phase especially for spring and autumn (Figure 6 and Figure 8). During that solar cycle phase (Solar maximum), many various solar events (high stream solar wind, coronal mass ejection, storm, etc.). 


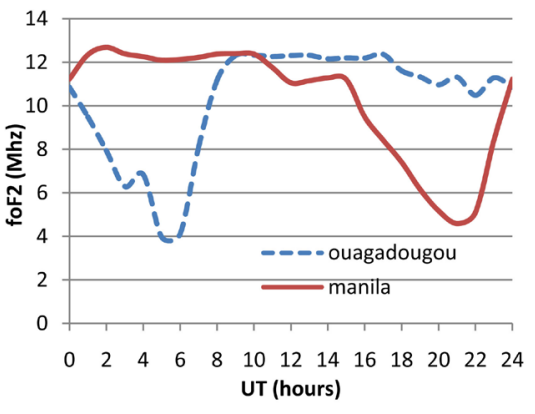

(a)

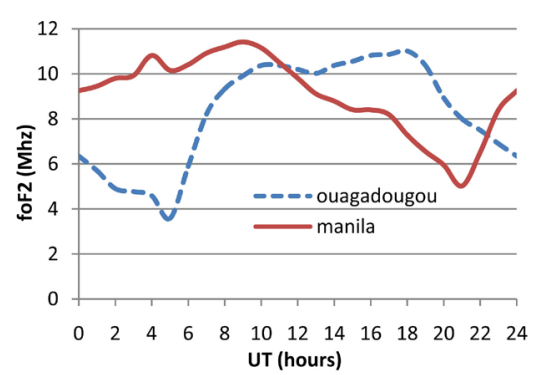

(c)

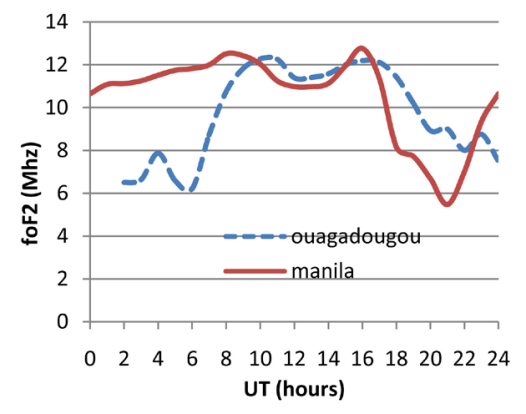

(b)

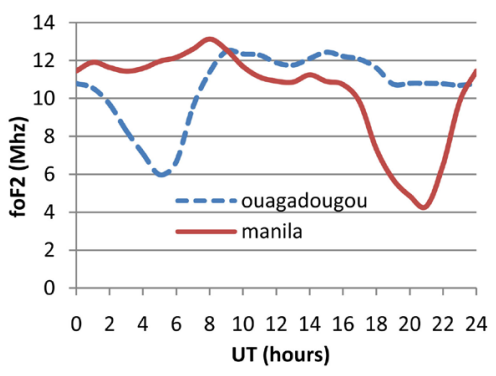

(d)

Figure 6. Seasonal variations of foF2 during cycle 20 maximum phase: (a) winter; (b) spring; (c) summer; (d) autumn.

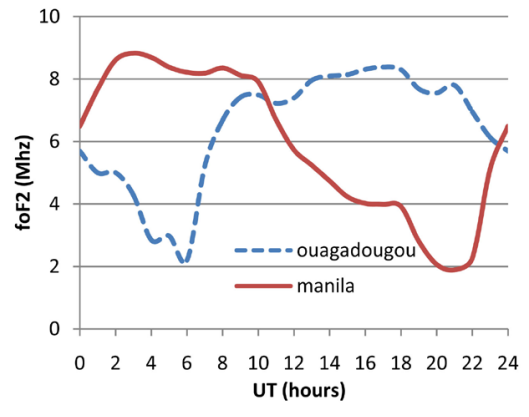

(a)

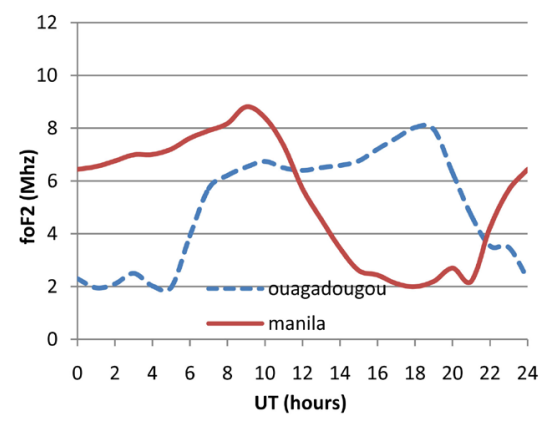

(c)

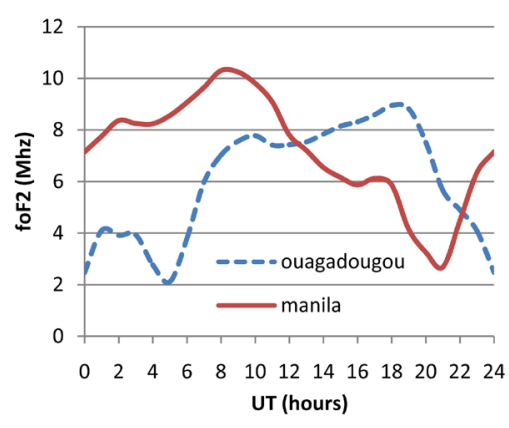

(b)

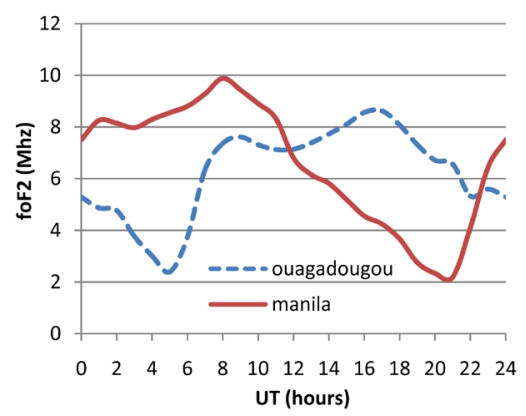

(d)

Figure 7. Seasonal variations of foF2 during cycle 20 minimum phase: (a) winter; (b) spring; (c) summer; (d) autumn.

These associated events may explain the various number of intersection points between measurements from Manila and Ouagadougou stations shown in Figure 6 and Figure 8. 


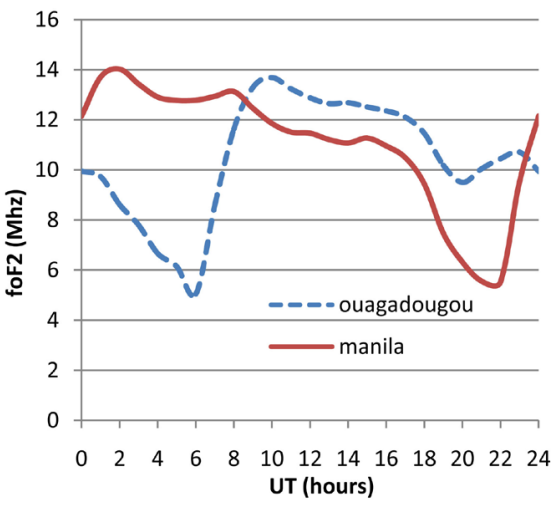

(a)

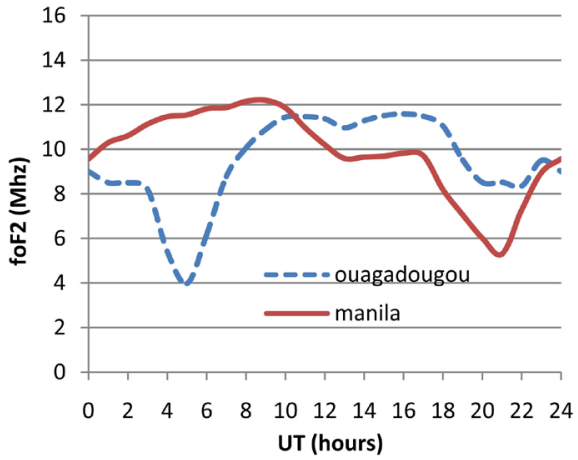

(c)

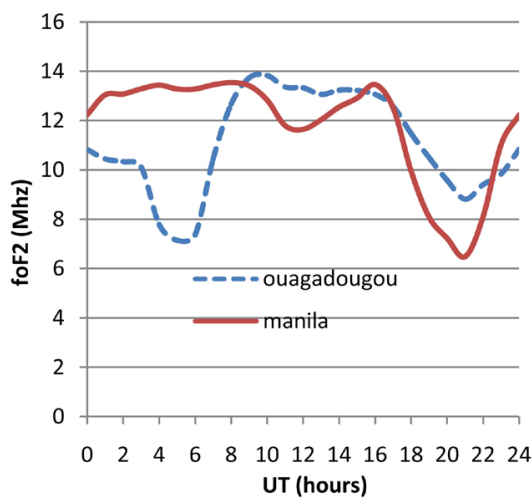

(b)

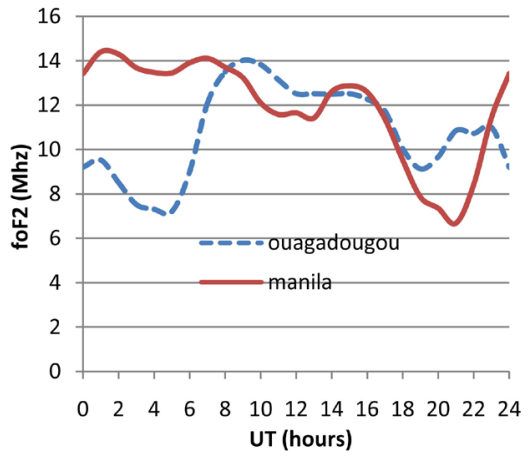

(d)

Figure 8. Seasonal variations of foF2 during cycle 21 maximum phase: (a) winter; (b) spring; (c) summer; (d) autumn.

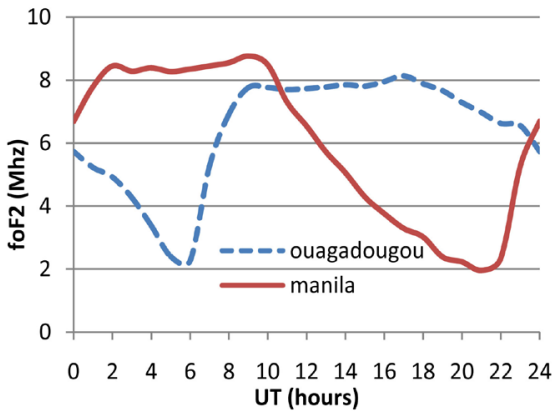

(a)

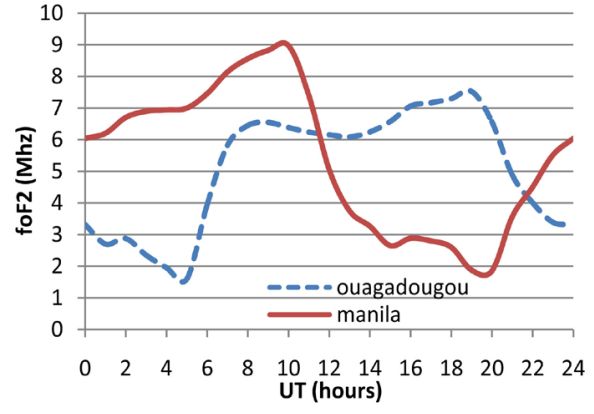

(c)

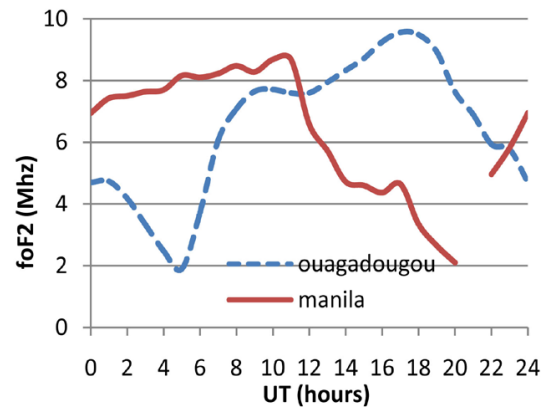

(b)

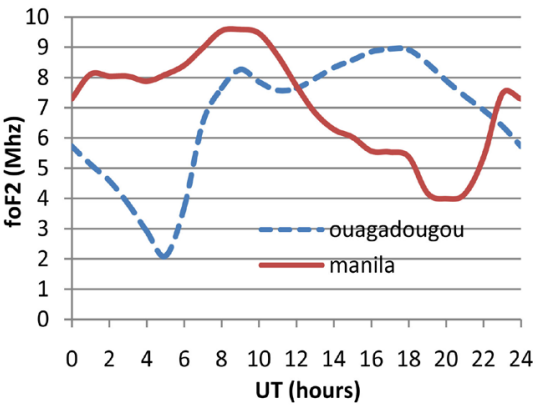

(d)

Figure 9. Seasonal variations of foF2 during cycle 21 minimum phase: (a) winter; (b) spring; (c) summer; (d) autumn. 
Table 1. foF2 most significant values maximum and during solar minimum for cycles 20 and 21 (W: winter; Sg: spring; S: summer; Au: autumn).

\begin{tabular}{|c|c|c|c|c|c|c|c|c|c|c|c|c|c|c|c|c|}
\hline \multirow[b]{3}{*}{ Seasons } & \multicolumn{8}{|c|}{ Solar Cycle 20} & \multicolumn{8}{|c|}{ Solar Cycle 21} \\
\hline & \multicolumn{4}{|c|}{ Maximum du cycle } & \multicolumn{4}{|c|}{ Minimum du cycle } & \multicolumn{4}{|c|}{ Maximum du cycle } & \multicolumn{4}{|c|}{ Minimum du cycle } \\
\hline & $\mathrm{W}$ & Sg & $S$ & $\mathrm{Au}$ & $\mathrm{W}$ & $\mathrm{Sg}$ & $S$ & $\mathrm{Au}$ & $\mathrm{W}$ & $\mathrm{Sg}$ & $S$ & $\mathrm{Au}$ & $\mathrm{W}$ & $\mathrm{Sg}$ & $S$ & $\mathrm{Au}$ \\
\hline $\begin{array}{l}\text { Ouagadougou } \\
\text { foF2 }(\mathrm{MHz})\end{array}$ & 12.36 & 12.27 & 11.01 & 12.42 & 8.83 & 8.94 & 8.02 & 8.62 & 13.68 & 13.83 & 11.59 & 14.02 & 8.13 & 9.56 & 7.52 & 8.94 \\
\hline $\begin{array}{c}\text { Manila } \\
\text { foF2 }(\mathrm{MHz})\end{array}$ & 12.88 & 12.51 & 11.42 & 13.13 & 8.83 & 10.30 & 8.81 & 9.88 & 14.02 & 13.54 & 12.20 & 14.40 & 8.76 & 8.68 & 8.97 & 9.59 \\
\hline
\end{tabular}

\section{Conclusions}

The results of our morphological investigations outlining the dependence of the foF2 variability on solar activity over different latitudes, different local times, and different seasons may be noted as follows:

1) Seasonally, the profiles of foF2 values measured at Manila and Ouagadougou stations are similar;

2) The magnitude of foF2 increases during high solar activity period (maximum) and decreases during low solar activity period (minimum);

3) During daytime measured data from Manila station are greater than those from Ouagadougou most of the time. That may lie in that Manila is closer to equatorial ionization crest region;

4) For these two stations solstice anomaly is observed and it is most pronounced during the intense geomagnetic activity (solar maximum) as summarized in Table 1 ;

5) During daytime, two remarkable intersection points (11:00 UT and 22:00 UT) are observed between the foF2 profiles from the two equatorial stations during solar minimum phase testifying to that there is a longitudinal effect on that F-layer parameter foF2. These crossing-points are independent of seasons and sunspot cycle phase;

6) Unlike minimum phase, there are several intersection points during maximum phase especially for spring and autumn. This may lie in the occurrences of several intense events (storms, CME, heliosheet fluctuations) during solar maximum phase.

\section{Acknowledgements}

The authors thank Brest Telecom for providing Ouagadougou ionosonde data and ISGI and SPIDR data centre for providing the aa indices and foF2 respectively.

Many thanks to IJG editors and anonymous reviewers of our paper.

\section{Conflicts of Interest}

The authors declare no conflicts of interest regarding the publication of this paper. 


\section{References}

[1] Ouattara, F. and Zerbo, J.L. (2011) Ouagadougou Station F2 Layer Parameters, Yearly and Seasonal Variations during Severe Geomagnetic Storms Generated by Coronal Mass Ejections (CMEs) and Fluctuating Wind Streams. International Journal of the Physical Sciences, 6, 4854-4860.

[2] Adeniyi, J.O. and Adimula, I.A. (1995) Comparing the F2-Layer Model of IRI with Observations at Ibadan. Advanced in Space Research, 15, 141-144. https://doi.org/10.1016/S0273-1177(99)80036-2

[3] Abdu, M.A., Batista, I.S. and DeSouza, J.R. (1996) An Overview of IRI-Observational Data Comparison in American (Brazilian) Sector Low Latitude Ionosphere. Advanced in Space Research, 18, 13-22. https://doi.org/10.1016/0273-1177(95)00893-4

[4] Batista, S., Abdu, M.A., De Medeiros, R.T. and De Paula, E.R. (1996) Comparison between IRI Predictions and Digisonde Measurements at Low Latitude Station. Advanced in Space Research, 18, 49-52. https://doi.org/10.1016/0273-1177(95)00899-3

[5] Bertoni, F., Sahai, Y., Lima, L., Fagundes, P., Pillat, V., Becker-Guedes, F. and Abalde, J (2006) IRI-2001 Model Predictions Compared with Ionospheric Data Observed at Brazilian Low Latitude Stations. Annales Geophysicae, 24, 2191-2200.

https://doi.org/10.5194/angeo-24-2191-2006

[6] Bilitza, D., Altadill, D., Zhang, Y., Mertens, C., Truhlik, V., Richards, P., McKinnell, L.A. and Reinisch, B. (2014) The International Reference Ionosphere 2012-A Model of International Collaboration. Journal of Space Weather and Space Climate, 4, A07. https://doi.org/10.1051/swsc/2014004

[7] Ouattara, F. and Fleury, R. (2011) Variability of CODGTEC and IRI 2001 Total Electron Content (TEC) during IHY Campaign Period (21 March to 16 April 2008) at Niamey under Different Geomagnetic Activity Conditions. Scientific Research and Essays, 17, 3609-3622. http://www.academicjournals.org/SRE https://doi.org/10.5897/SRE

[8] Tariku, Y.A. (2015) TEC Prediction Performance of the IRI-2012 Model over Ethiopia during the Rising Phase of Solar Cycle 24 (2009-2011). Earth, Planets and Space, 67, 140. https://doi.org/10.1186/s40623-015-0312-1

[9] Li, S., Li, L. and Peng, J. (2016) Variability of Ionospheric TEC and the Performance of the IRI-2012 Model at the BJFS Station, China. Acta Geophysica, 64, 1970-1987. https://doi.org/10.1515/acgeo-2016-0075

[10] Sawadogo, W.E., Zerbo, J.-L. and Ouattara, F. (2019) Diurnal Variation of F2-Layer Critical Frequency under Solar Activity Recurrent Conditions during Solar Cycles 21 and 22 at Ouagadougou Station: Prediction with IRI-2012. Scientific Research and Essays, 14, 111-118.

[11] Diabaté, A., Zerbo, J.-L. and Ouattara, F. (2019) Variation of the foF2 Parameter during Fluctuating Activity: Prediction with IRI-2012 Compared to Measured Data from Ouagadougou Ionosonde Station during Solar Cycles 21 and 22. Vietnam Journal of Earth Sciences, 41, 69-78. https://doi.org/10.15625/0866-7187/41/1/13549

[12] Faynot, J.M. and Villa, P. (1979) F-Region at the Magnetic Equator. Annales Geophysicae, 35, 1-9.

[13] Legrand, J.P. and Simon, P.A. (1989) Solar Cycle and Geomagnetic Activity: A Review for Geophysicists, Part I. The Contributions to Geomagnetic Activity of Shock Waves and of the Solar Wind. Annales Geophysicae, 7, 565-578. 
[14] Zerbo, J.L., Amory-Mazaudier, C., Ouattara, F., Legrand, J.P. and Richardson, J.D. (2012) Solar Wind and Geomagnetism, toward a Standard Classification 1868-2009. Annales Geophysicae, 30, 421-426. https://doi.org/10.5194/angeo-30-421-2012

[15] Clette, F., Svalgaard, L., Vaquero, J.M. and Cliver, E.W. (2014) Revisiting the Sunspot Number. A 400-Year Perspective on the Solar Cycle. Space Science Reviews, 186, 35-103. https://doi.org/10.1007/s11214-014-0074-2

[16] Zerbo, J.L., Ouattara, F., Zoundi, C. and Gyébré, A. (2011) Solar Cycle 21 and Geomagnetic Activity since 1868. Revue CAMES Serie A, 12, 255-262.

[17] Ouattara, F. (2013) IRI-2007 foF2 Predictions at Ouagadougou Station during Quiet Time Periods from 1985 to 1995. Archives of Physics Research, 4, 12-18.

[18] Danilov, A.D. and Mikhailov, A.V. (1999) Spatial and Seasonal Variations of the foF2 Long-Term. Annales Geophysicae, 17, 1239-1243. https://doi.org/10.1007/s00585-999-1239-2

[19] Kouris, S.S., Bradley, P.A. and Dominici, P. (1998) Solar Cycle Variation of the Daily foF2 and M(3000)F2. Annales Geophysicae, 16, 1039-1042. https://doi.org/10.1007/s00585-998-1039-0

[20] Pi, X., Mendillo, M., Spalla, P. and Anderson, D.N. (1995) Longitudinal Effect of Ionosphéric Response to Substorms at Middle and Lower Latitude: A Case Study. Annales Geophysicae, 13, 863-870. https://doi.org/10.1007/s00585-995-0863-8

[21] Echer, E., Gonzalez, W.D., Gonzalez, A.L.C., Prestes, A., Viera, L.E.A., Dal Lago, A., Guarnieri, F.L. and Schuch, N.J. (2004) Long-Term Correlation between Solar and Geomagnetic Activity. Journal of Atmospheric and Terrestrial Physics, 66, 1019-1025. https://doi.org/10.1016/j.jastp.2004.03.011

[22] Lastovcka, J., Yue, X. and Wan, W. (2008) Long-Term Trends in foF2: Their Estimating and Origin. Annales Geophysicae, 26, 593-598. https://doi.org/10.5194/angeo-26-593-2008

[23] Thiam, N., Ouattara, F., Gnabahou, A., Amory-Mazaudier, C., Fleury, R. and Duchuesne, P. (2011) Variation de la fréquence critique de la couche F2 de la station de DAKAR avec le cycle solaire. Journal des Sciences, 11, 16-20.

[24] Aarons, J. (1993) The Longitudinal Morphology of Equatorial F-Layer Irregularities Relevant to Their Occurrence. Space Science Reviews, 63, 209-243. https://doi.org/10.1007/BF00750769

[25] Babatunde, A., Olamike, R., Teiji, D.F., Nurul, U., Shazana, A.H., and Akimassa, Y. (2017) Longitudinal Variation of Equatorial Lectrojet and the Occurrence of Its Counter Electrojet. Annales Geophysicae, 35, 535-545. https://doi.org/10.5194/angeo-35-535-2017

[26] Abou, M.A. (2005) Equatorial Ionosphere-Thermosphere System: Electrodynamics and Irregularities. Advances Space Research, 35, 771-787. https://doi.org/10.1016/j.asr.2005.03.150

[27] Sterning, R.J. (1995) What Drives the Equatorial Electrojet? Journal of Atmospheric and Terrestrial Physics, 57, 1117-1128. https://doi.org/10.1016/0021-9169(94)00127-A

[28] Doumouya, V., Vassal, J., Cohen, Y., Fambitakoye, O. and Meurielle, M. (1998) Electrojet at African Longitude: First Results from Magnetic Measurements. Annales Geophysicae, 16, 658-666. https://doi.org/10.1007/s00585-998-0658-9

[29] Jadhav, G., Rajaram, M. and Rajaram, R. (2002) A Detailed Study of Equatorial Electrojet Phenomenon Using Oerted Satellite Observation. Journal of Geophysical Research: Space Physics, 107, 1175. https://doi.org/10.1029/2001JA000183 
[30] Alken, P. and Maus, S. (2007) Spatio-Temporal Characterization of the Equatorial Electrojet from CHAMP, Ørsted, and SAC-C Satellite Magnetic Measurements. Journal of Geophysical Research, 112. https://doi.org/10.1029/2007JA012524

[31] Rishbeth, H. and Muller-Wodarg, I.C.F. (2006) Why Is There More Ionosphere in January than in July? The Annual Asymmetry in the F2-Layer. Annales Geophysicae, 24, 3293-3311. https://doi.org/10.5194/angeo-24-3293-2006 